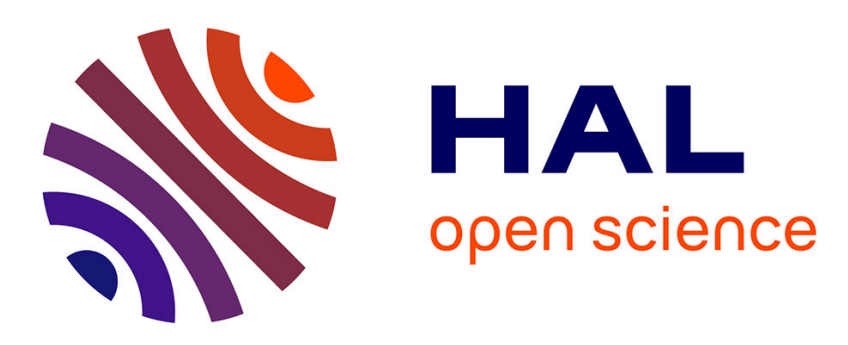

\title{
Design for IoT Business Modeling Workshop: A Case Study of Collaborative University-Industry Education Program
}

Satoshi Goto, Osamu Yoshie, Shigeru Fujimura

\section{To cite this version:}

Satoshi Goto, Osamu Yoshie, Shigeru Fujimura. Design for IoT Business Modeling Workshop: A Case Study of Collaborative University-Industry Education Program. 15th IFIP International Conference on Product Lifecycle Management (PLM), Jul 2018, Turin, Italy. pp.367-376, 10.1007/978-3-03001614-2_34. hal-02075547

\section{HAL Id: hal-02075547 \\ https://hal.inria.fr/hal-02075547}

Submitted on 21 Mar 2019

HAL is a multi-disciplinary open access archive for the deposit and dissemination of scientific research documents, whether they are published or not. The documents may come from teaching and research institutions in France or abroad, or from public or private research centers.
L'archive ouverte pluridisciplinaire HAL, est destinée au dépôt et à la diffusion de documents scientifiques de niveau recherche, publiés ou non, émanant des établissements d'enseignement et de recherche français ou étrangers, des laboratoires publics ou privés.

\section{(c)(1)}

Distributed under a Creative Commons Attribution| 4.0 International License 


\title{
Design for IoT Business Modeling Workshop: A Case Study of Collaborative University-Industry Education Program
}

\author{
Satoshi Goto ${ }^{1,2,3}$, Osamu Yoshie ${ }^{1,2}$, and Shigeru Fujimura ${ }^{1,2}$ \\ ${ }^{1}$ Graduate School of Information, Production and Systems (IPS), Waseda University, Japan \\ ${ }^{2}$ Waseda University IPS Kitakyushu Consortium, Japan \\ ${ }^{3}$ PTC Japan Co., Ltd., Tokyo, Japan \\ satoshi-gotolfuji.waseda.jp, yoshie@waseda.jp, \\ fujimura@waseda.jp
}

\begin{abstract}
On January 11, 2017, Waseda University launched a universityindustry collaboration program with a local government body in Kitakyushu City, Japan and 20 local businesses in the area. Officially called the "Waseda University IPS Kitakyushu Consortium (IPSKC)," the program aims to change the direction of local society and to develop innovative business and technology solutions in the era of Industry 4.0. In addition, it seeks to contribute to future global business development with neighboring Asian countries. As a first step, one of the program's key initiatives was to offer consortium members an Internet of Things (IoT) business modeling workshop as part of the University's industrial IoT/business engineering education program. This paper discusses an approach to facilitate workstream as a case study. We present the key results of the workshop; and discuss the future outlook of IoT and PLM education program.
\end{abstract}

Keywords: Internet of Things, Business Engineering, University-Industry Collaboration, Industry 4.0, Engineering Education, Workshop Facilitation, Design Thinking

\section{Introduction}

The Graduate School of Information, Production and Systems (IPS) at Waseda University focuses on academic studies related to the integration of manufacturing industry and information communication technology. The IPS campus is located in the middle of Kitakyushu City, the birthplace of Japan's modern industries (Fig. 1). Kitakyushu City is an industrial success story that managed to overcome environmental pollution that plagued the city in the 1960s [1]. However, the global business trend is changing to a new frontier of Industry 4.0. Therefore, it is also necessary to consider the impact of a new innovative business on the regional economy around Kitakyushu area (Fig. 2). 


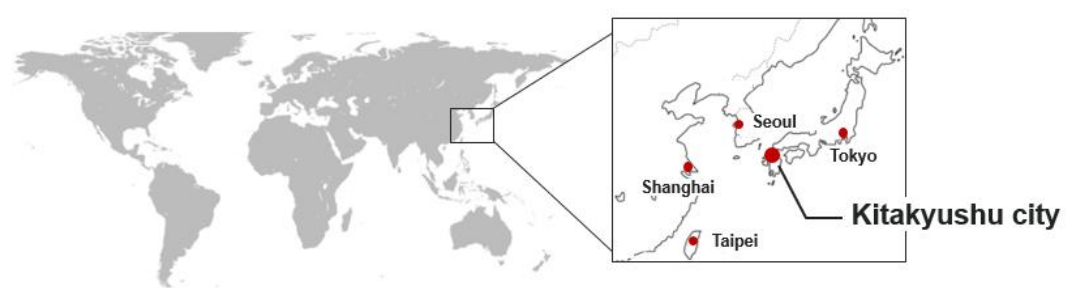

Fig. 1. The Location of Kitakyushu City, Fukuoka prefecture, Japan

In that context, Waseda University's IPS graduate school launched its new university-industry collaboration initiative, called the Waseda University IPS Kitakyushu Consortium (IPSKC), which involves partnering with the local government of Kitakyushu City and 20 local companies. As the area is a hub to the East Asia, IPSKC is also expected to contribute to future global business development for neighboring Asian countries. One of the key initiatives of the IPSKC in 2017 was to develop and deliver a first version of the university-industry collaborative workshop on the Internet of Things (IoT) as it relates to the business engineering education program.

This paper is a case study of the first IPSKC workshop. It begins with some background information on the key objectives of the IPSKC and on our previous studies on industrial IoT business workshop design. The paper focuses on the IPSKC IoT business modeling workshop that was held in spring of 2017. The workshop invited consortium members and IPS graduate students to participate. The intensive two-day workshop generated new insight and ideas about IoT-based business models. Finally, the key findings on the workshop along with a summary of its significance are presented.

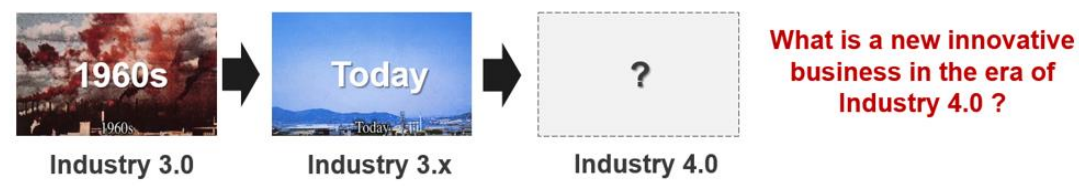

Fig. 2. New Innovative Business Direction on Industry 4.0 for Kitakyushu Area

\section{Mission of IPSKC Program}

The IPSKC [2] aims to be a model university-industry consortium in which the university collaborates with multiple IPSKC member companies rather than individual companies. It seeks to move beyond the conventional collaborative or commissioned research defined by contractual relationships to a dynamic ecosystem in which consortium activities spontaneously propagate between collaborative R\&D projects.

IPSKC members can serve as visiting faculty members of Waseda University IPS school in charge of the university-industry collaboration program. In 2017, it appointed four IPSKC members as lecturers. They taught the following industrial management courses: Leadership for Small Organization, Experiment on Industrial Internet of Things, Corporate Innovation, and New Industry Strategy. These types of aca- 
demic activities, available to both IPSKC members and IPS students, are a way of imparting practical business skills to students by IPSKC professional members (Fig. $3)$.

The program is also a means for companies to recruit IPS students and to provide IPS students with employment opportunities. It aims to have a positive impact on employment matching between students and companies. Furthermore, information shared through the IPSKC may be disseminated worldwide, thus establishing Kitakyushu City as the innovative center of smart manufacturing.
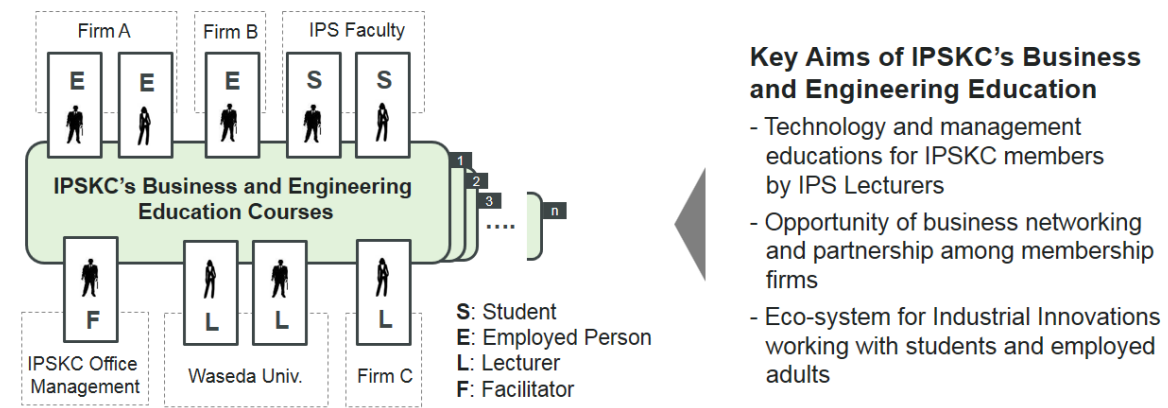

Fig. 3. Concept of IPSKC's Collaborative Educational Program

\section{Study Questions and Preliminary Activities}

\subsection{Study Questions}

When the IPSKC program was launched, we considered that only conducting conventional class room lectures does not promote innovation among students. The students should get a hands-on experience of Industry 4.0.

For example, many universities have been providing students a conventional sensor and PC board as an IoT starter kit [3][4]. However, this kit is used on a generic beginner scale and complex tools should be provided. This does not enable the participants to learn innovative business modeling.

With regards to business innovations, business schools have been already deployed and contributed for business strategy and management programs for adult employees and entrepreneurs. However, those are not always specific hands-on experience of IoT technology and solutions.

In terms of active learning type of group discussion, design thinking methodology is well-known in Japan as well as other counties [5]; customer value chain analysis, value graph, and paper prototyping are highly intriguing for the participants as they have a high potential to induce innovative thinking. However, it is hardly seen that references of design thinking workshops are included Industry 4.0 discussion themes.

Therefore, we have decided to test the following three preliminary studies that are combined with some state-of-the-art academic workshop practices. It can originally 
define a new workshop method on IoT-related business engineering for IPSKC members:

- Preliminary Study 1 - Design Thinking for IoT Vision Definition

- Preliminary Study 2 - Hands-on Technology Experience and Field Trip

- Preliminary Study 3 - New Business Modeling by Small and Medium sized En-

terprises (SMEs) Employees.

\subsection{Preliminary Study 1 - Design Thinking for IoT Vision Definition}

In January 2015, we started methodology development for multiparty workshop facilitation on IoT vision definition. This methodology adopted the design thinking methodology, which was developed by d.School of Stanford University (https://dschool.stanford.edu/), so that it efficiently builds a mutual new idea of IoT vision. Since 2013, design thinking was widely adopted in the university-industry collaboration programs in Japan.

However, fewer reports on design thinking have been identified in the IoT-related academic education field in Japan than in other countries in which design thinking has been adopted widely. Therefore, the first step was to propose a pragmatic IoT visioneering workshop framework as a preliminary study in Japan. In preliminary study 1, the framework evaluated 26 types of various IoT use cases defined by PTC Inc., which was systematized along entire product lifecycle management process [6]. The IoT use cases assisted in efficiently examining IoT business solutions. To discuss the 26 use cases efficiently, the authors proposed five progress steps as a IoT workshop facilitation (Table 1). When we had an opportunity to deploy this facilitation method to a Japanese manufacturing company at the time, they could define some new visions of the IoT business model in a very short time (within just two hours). It was able to get high evaluation from participants. However, owing to the short durations of the workshops, the participants suffered from pressure and stress.

In terms of such IoT discussion, understanding the technology was important as along with business management discussion. However, such a technology was not provided during the trial workshop sessions. As a result, the participants pointed out to the authors that the definition of IoT business model was undefined without the experience of IoT's technical knowledges. In addition, this workshop was designed and implemented for large sized global companies.

Therefore, it could not recognize a real value of university-industry collaboration program for SMEs.

Table 1. Five Steps for Group Facilitation at a Visioneering Session [7]

\begin{tabular}{c|l}
\hline Step & Group Discussion Topic \\
\hline 1 & Identify Stakeholder-utilizing Customer Value Chain Analysis (CVCA) \\
2 & Select Top 6 IoT Use Cases - aligning with corporate Value Drivers \\
3 & Narrow-down the Use Cases - - selecting 3 out of 6 for to be more specific \\
4 & Craft IoT Value Roadmap - positioning the Use Cases on the value maturity \\
5 & Set Metrics (KPIs)_qualifying Business Goals \\
\hline
\end{tabular}




\subsection{Preliminary Study 2 - Hands-on Technology and Field Trip}

On September 2016, we recruited some IPS student volunteers to participate in a 3day workshop [8], which included a hands-on IoT technology session using ThingWorx, a leading commercial IoT technology platform powered by PTC Inc (http://www.ptc.com/).

In addition, the day 3 included a field trip event around the industrial areas of Kitakyushu City, where many IPSKC member companies are located. In other words, we incorporated a business tour to discover new business model opportunities as much as possible during the workshop days (Fig. 4). This allowed the participants to develop the ability of insights on IoT technology and solution development that the participants could not imagine in classroom lectures.

Workshop participants were active IPS students and university officials. It was a great opportunity for them to understand the reality of the local society situation in which the IPSKC member are located.

However, since a lot more topics were covered in this workshop than those in the previous design thinking workshop, this workshop lasted for three days. This amount of time would discourage most working people from attending.

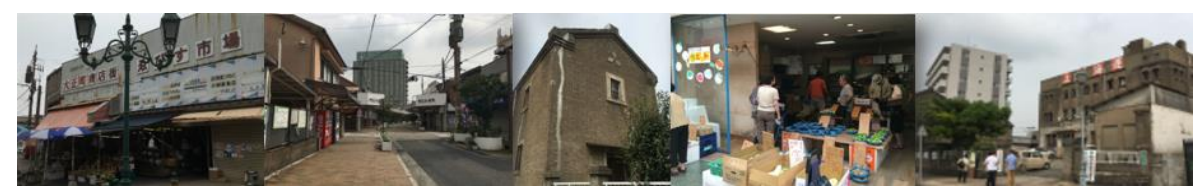

Fig. 4. The Target Local Town for Fieldwork Activity as the Workshop Day 3

\subsection{Preliminary Study 3 - New Business Modeling by SMEs Employees}

Through the results of previous preliminary studies 1 and 2, we identified that the combination of engineering and business education was valuable for the participants; the field trip was also a great activity to develop new insights for the business model for the participants. Therefore, we worked further as the third preliminary study to develop a workshop facilitation method on IoT business model design in March 2017. This was enhanced version of the past preliminary study 1 and 2 .

During the study, one of the IPSKC member companies (a local SME) was significantly interested in our workshop idea and tentative six sessions: Step A to F (Fig.5).
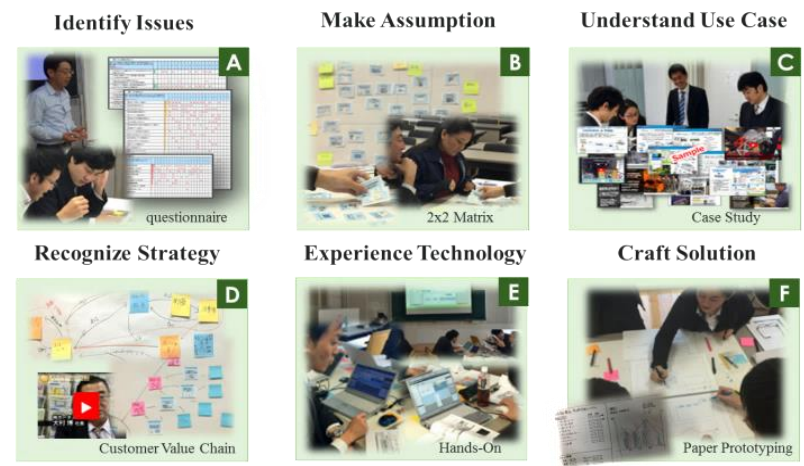

Fig. 5. Configured Six Sessions: A to F [9] 
The CEO proposed that he wanted to implement the workshop as a part of their employee education. This CEO feared about the existing business model becoming obsolete in the future. He raised expectations on the manner in which they could efficiently define ideas of new business models in a short time.

The result was quite positive according to the participants and their CEO. Particularly, while adopting customer value chain analysis (CVCA) [10], the participants could think of a new business model and its value chain, which they had never considered before. Because the workshop was conducted in a single day, it was highly satisfactory for adult workers.

However, this did not serve the original purpose of IPSKC as IPS students did not participate in this workshop.

\section{Case Study of IoT Business Modeling Workshop for IPSKC Members}

\subsection{Workshop Opportunity to IPSKC Members}

During the inception of the consortium in 2017, we reported to the board members on the outcomes of those three preliminary studies and proposed to deploy an industrial IoT business modeling workshop for selected IPSKC members. The proposed workshop agenda was an enhanced version adopting improvements and outcomes through the preliminary empirical studies. It was reinforced as more pragmatic session contents for the SMEs. The consortium board members have approved our proposal and implemented an IoT business modeling workshop.

\subsection{Workshop Agenda}

The following shows the workshop activities the authors recently executed with the IPSKC members.

\section{Date, Time, and Venue}

The workshop was held on June 8 and June 9, 2017; for the total duration over these two days was 13 hours (Table 2). The venue was a student lecture room in a building in Waseda University IPS campus. The participants gathered from individually owned companies and IPS graduate student communities.

\section{Involved Members}

The participants of the workshop were invited by IPSKC members. Twelve employees from IPSKC membership companies gathered; three graduate students from IPS of Waseda University also joined these employees. These 15 participants were divided into three groups during the two days. To efficiently conduct the workshop sessions, one professional workshop facilitator was assigned, who was a board member of IPSKC. One external IoT specialist supported them during the hands-on session of IoT application development (Fig. 6). 


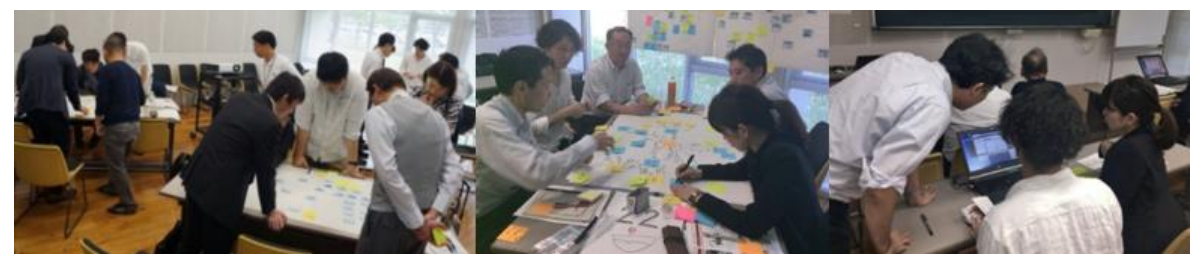

Fig. 6. The IPSKC Members Involved during the Two-Day Workshop

\section{Adopted Technology}

During the workshop sessions, ThingWorx was used as the IoT development platform, which was developed by PTC Inc. Fig. 7 shows the user interface and system architecture that was used by the participants in the hands-on technology session.
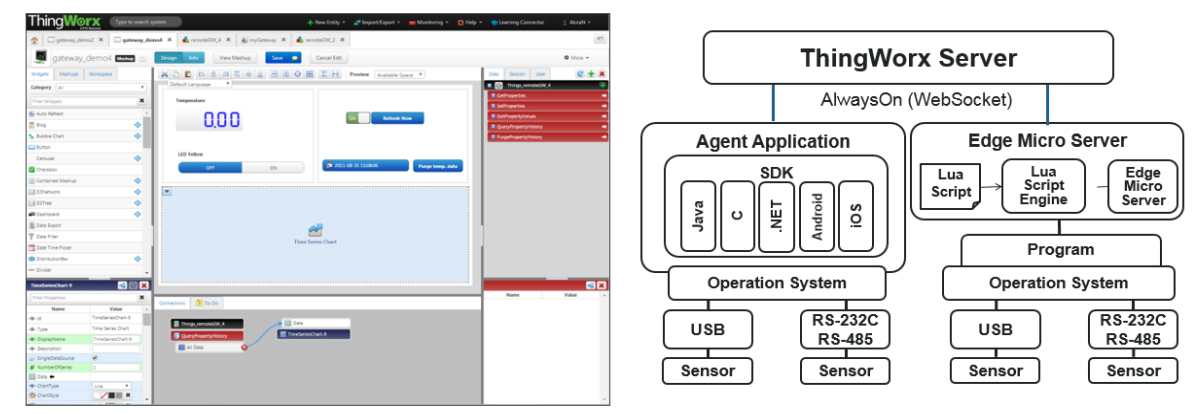

Fig. 7. User Interface (left) and System Architecture (right) of Commercial IoT Technology Platform: an example of ThingWorx by PTC Inc.

\section{Session Agenda and Timetable}

The workshop was configured for 15 sessions for two days. It was designed as an intensive program so that the participants could learn many IoT business and technology methodologies in a short time. The first day focused on understanding IoT solution development based on business strategy and experience of technology. The second day had a specific agenda of defining IoT-related business modeling via the business model canvas method [11]. This workshop aimed to comprehensively capture the participants' potential abilities through a group effort.

Table 2. The Agenda and Timetable of the Trial Workshop

\begin{tabular}{|c|c|c:c|}
\hline Step & Session Agenda & Interval & Clock Time \\
\hline & Day 1 (8-Jun-2017) & & \\
\hline 1 & Warming up, Self-Introduction & 15 & $10: 00-10: 15$ \\
\hline 2 & Review of Pre-Questionnaire by Participants & 30 & $10: 15-10: 45$ \\
\hline 3 & Understand of Existing IoT User Cases & 45 & $10: 45-11: 30$ \\
\hline & Group Lunch & 60 & $11: 30-12: 30$ \\
\hline 4 & Discuss about Business Objective adapting IoT apps. & 45 & $12: 30-13: 15$ \\
\hline 5 & Lecture of IoT Global Case Study & 30 & $13: 15-13: 45$ \\
\hline
\end{tabular}




\begin{tabular}{|c|c|c|c|}
\hline \multicolumn{2}{|r|}{ Break Time } & 15 & $13: 45-14: 00$ \\
\hline 6 & Hands-on of Commercial IoT Technology Platform & 120 & $14: 00-16: 00$ \\
\hline \multicolumn{2}{|r|}{ Break Time } & 15 & $16: 00-16: 15$ \\
\hline 7 & Define Customer Value Chain for IoT Value Propositions & 60 & $16: 15-17: 15$ \\
\hline 8 & Paper Prototyping of IoT Solution Candidates & 30 & $17: 15-17: 45$ \\
\hline 9 & Group Presentation & 15 & $17: 45-18: 00$ \\
\hline \multicolumn{4}{|c|}{ Day 2 (9-Jun-2017) } \\
\hline 10 & Reflection of Day 1 & 30 & $10: 00-10: 30$ \\
\hline 11 & Identify Target Market and Customers & 45 & $10: 30-11: 15$ \\
\hline 12 & Define Delivery Model and Resource Planning & 45 & $11: 15-12: 00$ \\
\hline \multicolumn{2}{|r|}{ Group Lunch } & 60 & $12: 00-13: 00$ \\
\hline 13 & Discuss about Revenue Stream and Cost Structure & 45 & $13: 00-13: 45$ \\
\hline \multicolumn{2}{|r|}{ Break Time } & 15 & $13: 45-14: 00$ \\
\hline 14 & Re-Design of Business Model & 30 & $14: 00-14: 30$ \\
\hline 15 & Final Group Presentation & 30 & $14: 30-15: 00$ \\
\hline
\end{tabular}

\subsection{Fieldwork at the Student Cafeteria: Developing an IoT Solution for a Future School Meal Management System}

One of key functions of the workshop was that we had been developing the process through which significant fieldwork should be provided to participants. Although field trips around the city and visits to companies allowed the participants to gain many insights, they were too time-consuming. We needed to create a realistic program that was not time-consuming.

Therefore, we conducted an activity in the student cafeteria located at IPS campus while the participants were having lunch. The participants were requested to observe the product and service lifecycle management and operations, such as carrying in foodstuffs, cooking, setting up meals, delivery provisions, payment, in service for eatin space, disposal, dish-washing, which were similar to those observed in an industrial manufacturing site.

Then, the participants were presented with the question "Please imagine what the student cafeteria will be in 2030?" They had to envision the business model that utilizes IoT solution for a future school meal management as a group work. The group members discussed the problems of the current school cafeteria concerning food processing and production system.

\section{Discussions}

The purpose of the study was to determine whether participants were able to design an IoT-based business model built for the Industry 4.0 era during the workshop. To achieve this, we used a questionnaire that the participants had to answer at the end of the workshop. 
We received feedback from 12 among the 15 participants. The results of the questionnaire are summarized below:

Question 1: Please evaluate your overall satisfaction of the workshop.

Results: $58 \%$ of participants reported being "strongly satisfied," and $42 \%$ reported being "satisfied." No participant reported being "not satisfied."

It appears that the majority of the participants comprehensively understood the value of the workshop agenda and contents.

Question 2: What methodology did you to consider to be the most effective in generating new ideas?

As stated in Fig. 8, the trial workshop was an opportunity for many participants to learn about market-proven design thinking methodologies, such as CVCA, business model canvas, and value graph.

Question 3: Did you discover a new IoT business model during the workshop?

Among the participants, $33 \%$ reported that they were able to formulate a new IoT business model using the methodologies provided and within the workshop timeframe. No participant reported not defining a new business model at all. However, $67 \%$ reported "It was unknown," meaning that it was unclear to them whether they did manage to come up with a new innovative business model during the workshop. We will need to thoroughly investigate the "it was unknown" response.

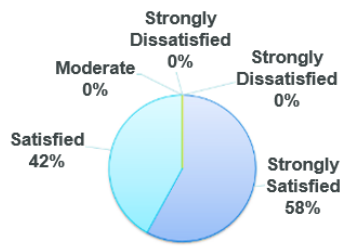

Result of Question 1

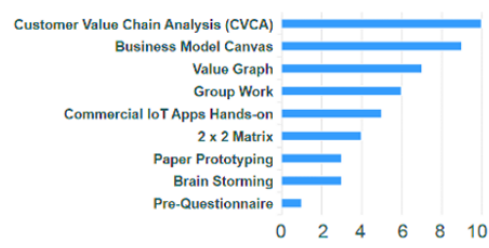

Result of Question 2

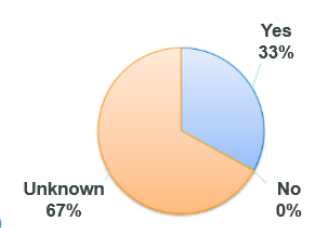

Result of Question 3

Fig. 8. Evaluation Results of Workshop by Participants

\section{Conclusion and Future Work}

The two-day IoT business modeling workshop was designed to provide IPSKC participants. This was an opportunity to engage in industrial IoT business modeling using technologies and business strategies introduced in the workshop. The following outcomes were identified:

- The basic method of design thinking was adopted to gather many of insights. This contributed to efficiently produce an innovative business hypothesis.

- The user experience of state-of-the-art commercial IoT application software supported the participants to make the innovative business hypothesis.

- There was a possibility to create new business models while working with multiparty groups involving adult employees as well as students.

- To create a new business model, the agenda of workshop was needed to enhance more of the current workshop agenda and contents. 
The short-term intensive business workshop conducted over two days enabled a sense of achievement among the participants.

Future work includes a several days intensive education program offered to IPSKC members in summer 2018, which would be an expansion of the IoT business modeling workshop and a plan to convert the modeling program to a university credited course combined with PLM education category.

Acknowledgments. This work was supported by The Japan Society for the Promotion of Science (JSPS) Grant-in-Aid for Scientific Research (C) No.15K00495.

\section{References}

1. Shiroyama H., Kajiki S.: Case study of Eco-town Project in Kitakyushu: tension among incumbents and the transition from industrial city to green city. In: Governance of urban sustainability transitions. Springer, Tokyo. p. 113-132. (2016)

2. Waseda University IPS Kitakyushu Consortium, https://www.waseda.jp/fsci/ipsrc/about/\#anc_9 (in Japanese). Accessed 11 Mar 2018

3. Cai K., Tie F., Huang H., Lin H., Chen H.: Innovative Experiment Platform Design and Teaching Application of the Internet of Things. International Journal of Online Engineering (iJOE), 11(6), pp.28-32 (2015)

4. He J., Lo D.C.T., Xie Y.: Integrating Internet of Things (IoT) into STEM undergraduate education: Case study of a modern technology infused courseware for embedded system course. Frontiers in Education Conference (FIE), IEEE (2016)

5. Koh J., Chai C., Wong S., B., and Hong H. Y.: Design Thinking for Education. Springer (2015)

6. PTC Inc.: IoT Value Roadmap, https://www.ptc.com/en/products/iot/use-cases. Accessed 11 Mar 2018

7. Goto S., Trolio E., Yoshie O., and Tamaki K.: Multi-party Interactive Visioneering Workshop for Smart Connected Products in Global Manufacturing Industry Considering PLM. 13th IFIP WG 5.1 International Conference on Product Lifecycle Management, pp.501-511 (2016)

8. Goto S., Yoshie O., Fujimura S., and Tamaki K.: Preliminary Study on Workshop Facilitation for IoT Innovation as Industry-University Collaboration PLM Program for Small and Medium sized Enterprises. 14th IFIP WG 5.1 International Conference on Product Lifecycle Management (2017).

9. Goto S., Yoshie O., Fujimura S.: Industrial IoT Business Workshop on Smart Connected Application Development for Operational Technology (OT) System Integrator. The IEEE International Conference on Industrial Engineering and Engineering Management (2017)

10. Donaldson K., Ishii K., Sheppard S.: Customer Value Chain Analysis. Research in Engineering Design16.4, 174-183 (2006)

11. Osterwalder A., Pigneur Y.: Business model generation: a handbook for visionaries, game changers, and challengers. John Wiley \& Sons. (2010) 